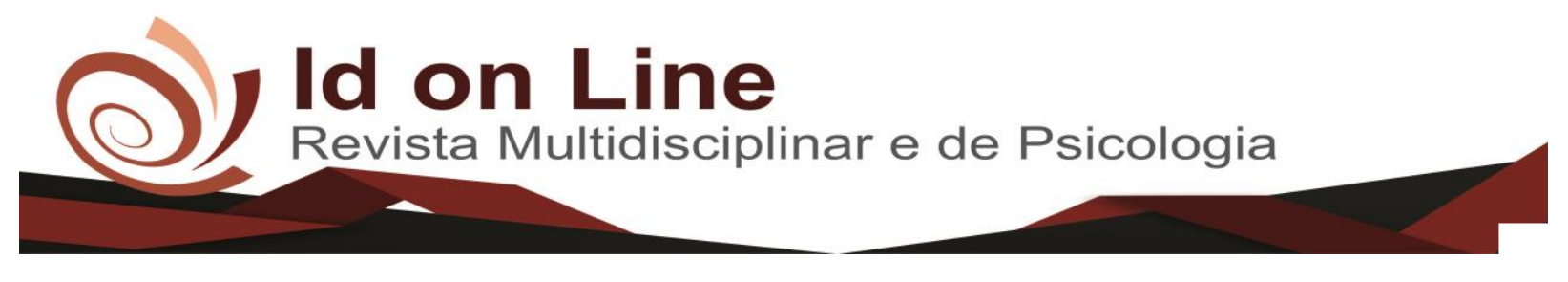

Artigo

\title{
Marketing Digital: \\ Um Estudo Multicasos em Bares e Restaurantes de Crato-CE
}

\author{
Jackson Bruno Feitosa Araújo ${ }^{1}$ Joyce da Silva Albuquerque ${ }^{2}$
}

\begin{abstract}
Resumo: Essa pesquisa tem por objetivo analisar se as empresas selecionadas para esse estudo, nas quais trabalham no seguimento de bares e restaurantes em Crato-CE, tem se utilizado das ferramentas do marketing digital. Essa pesquisa é definida como um estudo de multicasos, seguindo uma abordagem qualitativa, com característica descritiva, de meios bibliográficos. A pesquisa foi realizada em três estabelecimentos localizados na cidade de Crato-CE. Para a coleta de dados foi realizada uma entrevista junto aos gestores e/ou proprietários dos estabelecimentos. Os dados foram analisados por meio da análise de conteúdo. Os resultados encontrados apontam que o marketing digital vem sendo praticado por bares e restaurantes da cidade do Crato-CE, mas de uma forma ainda amadora, por conta da inviabilidade financeira em manter um funcionário exclusivo para essa função e alto custo na contratação de uma empresa especializada para a produção de conteúdo digital de qualidade.
\end{abstract}

Palavras Chave: Marketing. Marketing Digital. Ferramentas do Marketing.

\section{Digital Marketing: A Multicountry Study in Crato-Ce Bars and Restaurants}

\begin{abstract}
This research has the objective of analyzing whether the chosen companies for this study, bars and restaurants in Crato-CE, have been using digital marketing tools. This research is defined as a multicase study, following a qualitative approach, with a descriptive characteristic, of bibliographic means. The research will be conducted in three establishments located in Crato-CE. For the collection of data an interview will be held with the managers and / or owners of the establishments. Data will be analyzed through content analysis. The results show that digital marketing has been practiced by bars and restaurants in the city of Crato-CE, but in a still amateurish way, because of the financial impracticability of maintaining an exclusive employee for this function and high costs in hiring a specialized company for the production of quality digital content.
\end{abstract}

Keywords: Marketing. Digital Marketing. Marketing Tools.

\section{Introdução}

O Marketing pode ser entendido como a junção de elementos que intervém nos desejos humanos, a fim de alcançar objetivos específicos, sendo indispensáveis no comércio mundial (MOREIRA et al., 2013).

\footnotetext{
${ }^{1}$ Graduando do curso de Administração do Centro Universitário Doutor Leão Sampaio/Unileão. Contato: bruno_feitosa@outlook.com.br

${ }^{2}$ Professora Orientadora do Centro Universitário Doutor Leão Sampaio/Unileão, mestre em administração. Contato: joyce@leãosampaio.edu.br
} Id on Line Rev. Mult. Psic. V.12, N. 42, p. p. 719-742- ISSN 1981-1179
Edição eletrônica em http://idonline.emnuvens.com.br/id 
Com a grande disputa de mercado, e com a finalidade de obtenção de sucesso e satisfação da clientela, as organizações precisam reconhecer as reais necessidades e desejos do seu consumidor alvo, essa visão fará com que esses se adaptem de modo mais eficiente que seus concorrentes. Sendo assim, o conceito primordial por trás do marketing é o de satisfazer as expectativas humanas (MOREIRA et al., 2013), como afirmam Kotler e Keller (2006) no qual definem "Marketing é a atividade humana dirigida para satisfazer necessidades e desejos por meio de troca".

No ano de 2002, no Brasil, deu-se a inicialização da popularização da internet. Nesse período, os investimentos nas mídias digitais eram escassos, porém aos poucos se foi descobrindo o grande poder de envolvimento que essas tinham com o público; logo, em 2008, com a economia mais aquecida, houve recordes nas vendas de computadores e telefones celulares, a introdução da TV Digital no Brasil, mudando completamente a vida das pessoas (CINTRA, 2010). De acordo com Cobra (2009), “O Marketing no Brasil, que se espelha em uma realidade de um país de crescimento acelerado, é hoje fonte de referência mundial para a disseminação da cultura e do conhecimento mercadológico”.

Como estratégia mercadológica, o Marketing Digital vem ganhando espaço em virtude da expansão da internet, segundo Amaral (2004) isso aconteceu devido alguns princípios essenciais de redes de computadores, sendo dois deles o compartilhamento de recursos e a alta confiabilidade econômica. O Marketing Digital é a aplicação dos conceitos básicos de marketing no meio digital, especialmente na internet, na qual é a maior rede de interconexão atualmente. Graças a essa interligação entre a rede e a colocação do marketing, pode-se construir no meio digital, um serviço altamente conhecido e forte (REINO, 2010).

De acordo com dados da $27^{\circ}$ Pesquisa Anual de Administração e Uso de Tecnologia da Informação nas Empresas, realizada pela Fundação Getúlio Vargas, em 2017, o Brasil em 2018 chegará a ter dois dispositivos conectados à internet, por habitante, alcançando assim o número de 416 milhões de aparelhos no país. (FOLHA DE SÃO PAULO, 2017). É nesse cenário que se percebe que uma das principais tendências da atualidade é o crescimento das ações mobile marketing, na qual podemos definir como uma ação de marketing realizada através de celulares e dispositivos móveis (CINTRA, 2010). O que é visto nos dias de hoje é que essa prática se tornou uma forte aliada nos empreendimentos alimentícios brasileiros. 
Tendo em vista esse avanço tecnológico no mercado, esse estudo buscou verificar se as ações de marketing Digital já estão sendo realizadas por bares e restaurantes, na cidade de Crato-CE, sendo essas eficazes ou não, a partir do momento da sua aderência.

O marketing muitas vezes é visto apenas como vendas e publicidade, mas estas são apenas estratégias que compõem uma parte daquilo que é o marketing. As ideias que compõe o conceito de marketing atualmente ressaltam a importância da construção de um relacionamento satisfatório, a longo prazo, no qual tanto os consumidores como as organizações obtenham aquilo que desejam.

Com as mudanças que ocorrem de forma constante no mercado, a maneira de fazer negócio tem mudado. Nunca o consumidor teve à sua disposição uma gama tão grande de produtos, serviços, informação e publicidade. Diante de tal situação, o cliente sente-se afetado por tantas ofertas e tende cada vez mais a focar naquilo que realmente lhe interessa, ignorando o que não lhe importa. Além disso a forma de comprar também vem mudando, atualmente cada vez mais pessoas utilizam-se da internet para realizarem pesquisa de preço ou para realizarem compras em lojas virtuais. Deste modo é de extrema importância que as empresas se façam presente nos ambientes que despertam interesse de seus consumidores e assim o marketing digital vem se destacando como um conjunto de estratégias que possibilitam uma gama de oportunidades de comunicação, interação, relacionamento e mensuração de resultados entre as empresas e seus consumidores. (TORRES, 2009).

Segundo Chaffey et al. (2009), o marketing digital tem como função, não só, a criação da melhor oferta para o seu público-alvo e a articulação da mesma com os outros canais, mas também, a seleção dos investimentos mais apropriados, em software, hardware e outros recursos que melhorem a experiência do consumidor e providenciem melhores resultados aos canais digitais. Além disso, o marketing digital possui ferramentas que proporcionam uma série de benefícios as organizações, como redução de custos, maior visibilidade da marca, maior interação com o público alvo, entre outros benefícios.

Deste modo e com base no que foi exposto, surgiu como pergunta norteadora deste trabalho se as empresas que trabalham no seguimento de bares e restaurantes em Crato-CE têm se utilizado das ferramentas do marketing digital? 
Foram analisados se as empresas selecionadas para pesquisa, pelo método de apontamento, nas quais trabalham no seguimento de bares e restaurantes em Crato-CE, tem se utilizado das ferramentas do marketing digital.

Para atender os objetivos deste trabalho, foi proposto como objetivos específicos: 1) Averiguar por meio de referencial teórico o desempenho das mídias digitais no mercado global; 2) Verificar se houve alguma mudança positiva, para os respectivos estabelecimentos a partir do momento em que se optou pelo uso das mídias digitais como estratégia de marketing; 3 ) Verificar se as empresas utilizam indicadores que demonstrem os resultados das mídias digitais nos estabelecimentos; 4) Analisar quais as principais dificuldades para a implantação das estratégias de marketing digital nas organizações.

O presente artigo expõe um aprofundamento sobre um tema ainda pouco explorado, principalmente se tratando na realidade da cidade de Crato-CE, trazendo por tanto uma contribuição acadêmica e mercadológica aos estudantes pesquisadores, empresários, gestores e demais interessados sobre a utilização do marketing digital como ferramenta estratégica nas organizações.

O artigo teve propósito de averiguar os benefícios e o potencial que o marketing digital pode oferecer em relação aos métodos convencionais de marketing, mostrando para os gestores toda sua eficiência perante o mercado. O estudo também relata que com as constantes mudanças vividas pelas empresas o marketing vem sendo um importante aliado, para as mesmas, adaptarem-se as novas realidades.

\section{Referencial Teórico}

\section{Marketing}

O marketing, ao longo das décadas, apresentou diferentes contextualizações, que foram aplicadas nas organizações. Diante disso, Las Casas (2017) afirma que o marketing sempre foi praticado, uma vez que em qualquer década da comercialização, os fatores e as variáveis eram sempre levadas em conta, oscilando apenas a intensidade em que eram utilizados. Já Kotler (2017), diz que as ações de marketing evoluíram ao longo dos anos de tal forma, que ele as 
nomeou de marketing 1.0, 2.0, 3.0 e 4.0, sendo que o 1.0 está diretamente relacionado a produção, 2.0 as vendas e o 3.0 a relacionamento com o cliente e o 4.0 com a revolução digital. Além disso, Cobra (2017) define marketing como a principal ferramenta para o melhoramento continuo de produtos e serviços, visando a satisfação total dos clientes. Isso acontece quando se define um público-alvo, entende suas necessidades e gerenciam as ações para satisfazê-lo, e então obter lucro.

Perante os conceitos relacionados, subentende-se que o marketing tem como principal função, além da obtenção de lucros, a satisfação dos seus clientes e também um relacionamento mais próximo com os mesmos, procurando sempre os entender para que possam assim tomar ações e assim suprir suas necessidades (CHURCHILL; PETER, 2013). Por isso, para atender e satisfazer os desejos dos consumidores, o marketing está em constante processo de evolução, como mostra na Tabela 1.

Tabela 1. Evolução do pensamento de marketing

\begin{tabular}{|c|c|c|}
\hline Escola Funcional & 1900 & $\begin{array}{l}\text { Criado no início de } 1900 \text {, } \\
\text { com foco nas atividades } \\
\text { necessárias para executar as } \\
\text { transações de marketing e } \\
\text { nos métodos de execução } \\
\text { dessas transações. }\end{array}$ \\
\hline Escola Administrativa & 1950 & $\begin{array}{l}\text { Foco na determinação das } \\
\text { necessidades } \\
\text { consumidores, no marketing } \\
\text { mix, na segmentação de } \\
\text { mercado, na miopia do } \\
\text { marketing. }\end{array}$ \\
\hline $\begin{array}{c}\text { Marketing de } \\
\text { Relacionamento }\end{array}$ & 1980 & $\begin{array}{l}\text { Foco na criação de lealdade e } \\
\text { na satisfação e retenção de } \\
\text { clientes }\end{array}$ \\
\hline Cybermarketing & 2000 & $\begin{array}{l}\text { Trabalhar na personalização } \\
\text { em massa, proporcionar } \\
\text { rapidez no processamento de } \\
\text { transações e permitir alta } \\
\text { interatividade com o cliente }\end{array}$ \\
\hline
\end{tabular}

Fonte: Adaptado Miranda (2004); Arruda (2004).

O marketing cresceu e evoluiu, trazendo os mais diversos conceitos, com ele surgiram, também, algumas ramificações que o auxiliam na expansão da relação entre as organizações e 
clientes, dentre estas o marketing digital. Sendo eles, Marketing de Posicionamento, Marketing de Conteúdo, Marketing de Relacionamento, Marketing de Guerrilha e o Marketing Digital.

\section{Marketing Digital}

De acordo com Torres (2009) o marketing digital não é um novo estilo de marketing ou uma reinvenção desse, mas sim a utilização de uma nova ferramenta para a prática de marketing, essa utiliza-se da internet, envolvendo assim comunicação, publicidade, propaganda e todas as possibilidades de estratégias e conceitos já familiares na teoria do marketing. Com isso, podese afirmar que o marketing digital é o emprego de estratégias no meio digital que utilizam ferramentas e teorias já conhecidas do marketing.

Esse modelo de marketing pode ser observado como resultado de uma conectividade mais representativa na atualidade. Ele responde de acordo com as necessidades formadas pela inovação tecnológica da comunicação, por causa da internet e da web 2.0 que vem reformulando o comportamento do consumidor (OLIVEIRA, 2011).

Sendo assim o marketing digital permite que o cliente seja produtor e consumidor da informação, isso porque seu uso possibilita a elaboração e o compartilhamento de informações de conteúdos pelos usuários, e para os usuários (TORRES, 2009).

Segundo Gabriel (2010) as empresas precisam, primeiramente, se ver dentro do mercado digital para depois pensar em empreender esforços com as ações de marketing digital. "A presença digital, da mesma forma que a empresa/marca deve estar totalmente alinhada com o posicionamento da marca/produto e oferecer a melhor relação possível entre a experiência para o público e o retorno para a marca" (GABRIEL, 2010).

Sendo essa pesquisa relacionada a empresas com segmentos em bares e restaurantes, o marketing digital geralmente é desenvolvido a partir de algumas ferramentas relacionadas a esse meio, sendo elas: YouTube, as redes sociais, Google AdWords e Google AdSense. 
YouTube

Criado em 2005, o YouTube é de domínio do Google. O site proporciona, gratuitamente, aos usuários a criação de canais para compartilhamento e armazenamento de vídeos em formato digital. O canal pode ser personalizado de acordo com seu proprietário, sendo capaz de atribuir o nome da marca, imagens de fundo e descrição (SANTOS, 2014).

Quando se compartilha um vídeo no Youtube, há o aparecimento de um campo próprio para comentários, onde outros usuários podem interagir sobre o conteúdo exposto, como também podem avaliar o vídeo e os comentários de outros integrantes do site como bons ou ruins. Além desse meio de interação, há também o modo de compartilhamento do vídeo em outras redes sociais, sendo algumas delas: Facebook, Twitter, Google+ e Tumblr. Pode-se também incorporar o conteúdo em um site pessoal, página, blog ou enviar por e-mail (SANTOS, 2014).

O YouTube usa da estratégia de sugerir vídeos que façam referência aos conteúdos mais procurados pelos frequentadores da página, o site também disponibiliza anúncios gráficos que ficam localizados estrategicamente nos resultados de pesquisas que são também associados a esses anúncios. Além também de permitir que os anunciantes desfrutem da possibilidade de terem seus conteúdos na homepage do site, com privilégio, durante 24 horas (SANTOS, 2014).

Existem várias formas de se anunciar algo no YouTube, Santos (2014) dá o exemplo do TrueView, essa maneira exibe vídeos sem a seleção prévia dos usuários, os vídeos são passados por 5 segundos obrigatórios, podendo depois desse tempo ser pulado o anúncio, sendo cobrada somente as visualizações completas.

\section{Redes Sociais}

As redes sociais na internet são capazes de selecionar e difundir informações que possam ser consideradas importantes pelos seus membros. A seleção é voltada para a elaboração de novas informações, na discussão e ampliação da movimentação de informações já difundidas previamente por veículos noticiosos (RECUERO, 2009). 
De acordo com Sinclaire e Vogus (2011), na visão mercadológica, há uma alteração no equilíbrio do poder de troca entre as organizações e os consumidores, a partir das redes sociais, isso porque essas ferramentas dão a liberdade de compartilhamentos de diversas informações sobre um determinado produto e serviços. Esses efeitos repercutem em alterações, sendo uma delas a mudança na estratégia corporativa, que aderem ao uso destas plataformas com a intenção de restabelecer o equilíbrio de tais forças. Os mesmos autores também parafraseiam sobre algumas características motivadoras ao uso das redes sociais pelas empresas, sendo elas a facilidade de implementação e a possibilidade de contato mais estreito com clientes e consumidores.

A implementação das redes sociais nas empresas pode ser feita de três formas distintas: desruptiva, gradativa ou emergente. A primeira citada é indicada para organizações de pequenos grupos, sua implantação é realizada simultaneamente em todos os setores; a gradativa é feita a partir de projetos-piloto em departamentos na qual a equipe já está mais adaptada com as ferramentas, fazendo com que o momento de aprendizagem seja mais seguro, já o emergente apodera-se das capacidades de conhecimento tecnológico dos próprios funcionários, isso faz com que esses estimulem, espontaneamente, seus colegas de trabalho, gerando um ciclo de propagação parecido com ao dos virais (JUE; MARR; KASSOTAKIS. 2010).

De acordo com Hasgall e Shoham (2007), o sucesso das redes sociais se dá pela transformação do conhecimento planejado em explícito, ao mesmo momento em que esse conhecimento se torna acessível e compartilhável por qualquer usuário. Isso mostra que a tecnologia não está a serviço apenas da manutenção dos processos de controle e de modelo hierárquico de estrutura.

\section{Google AdWords}

O Google oferece, gratuitamente, ferramentas para os profissionais de marketing digital, nos quais geram diversos benefícios para esses, como segurança e rapidez nas suas atividades. Além disso, possibilita a esses especialistas o monitoramento minucioso de suas campanhas, como também aperfeiçoa páginas, aumenta a quantidade de leads e conversões por meio de anúncios, entre outros. Uma ferramenta oferecida pelo Google ideal para a aplicação em 
empresas com segmento de bares e restaurantes é o Google Adwords (BRITO; MALHEIROS, 2013).

De acordo com Brito e Malheiros (2013) “o GoogleAdwords é a ferramenta oferecida para a criação de anúncios e a seleção de palavras-chave apropriadas para tal”. Esses anúncios situam bem o site de uma determinada marca na página principal de buscas do Google, pois quando o consumidor digita as palavras-chaves relacionadas com sua pesquisa no campo de busca, esses se diferenciam da busca convencional sendo expostos com um melhor posicionamento e com cores e letras diferentes. Outro benefício para as empresas é que os anúncios podem ser empregados em vários formatos e segmentados para diferentes lugares e idiomas. Além disso, a cobrança para tal ferramenta só é gerada quando o usuário clica no anúncio, isto é, a partir de cada clique ou CPC é gerado um custo ao anunciante (BRITO; MALHEIROS, 2013).

Araújo e Santos (2017) também discorrem sobre a finalidade da ferramenta Google Adwords na qual "trata da venda de publicidade para empresas interessadas em anunciar no buscador na procura de maior visibilidade no meio virtual. $\mathrm{O}$ diferencial da propaganda no Adwords é a personalização do anúncio". Os mesmos autores também ressaltam que se o anúncio não estiver tendo o êxito esperado, o anunciante poderá alterá-la para melhor adequar ao público, como também desativá-la caso deseje (ARAÚJO; SANTOS, 2017).

\section{Google AdSense}

Brito e Malheiros (2013) também discorrem sobre o Google AdSense, de acordo com os autores essa ferramenta é conhecida, basicamente, por gerar um lucro de acordo com a movimentação de visitantes do site. Os mesmos explicam que o funcionamento se dá da seguinte forma:

Existe um código que é inserido em todas as páginas do site por meio do qual a ferramenta cria espaços para publicidades com anúncios gerados automaticamente dentro do site. Toda vez que algum usuário clica em um anúncio, o site ganha um valor pré-definido que depende do anúncio no qual o visitante clicou. É possível escolher receber o pagamento por clique ou por impressão do anúncio. 
Porém, por mais que o Google AdSense seja vantajoso para o anunciante, ele tem seu ponto negativo, pois os anúncios são aleatórios e definidos pelo Google, levando a exposição do anúncio de uma forma que não convém, podendo ser aventuroso, mas, por mais que haja essa lacuna a presente ferramenta ainda reproduz grande possibilidade de lucro para a marca (BRITO; MALHEIROS, 2013).

Biancovilli et al. (2006) fala que o Google AdSense foi desenvolvido para os editores de sites, isso porque ele fornece instantaneamente anúncios gráficos e de texto que são benéficos para seu site e conteúdo. Os anúncios são adaptados de tal maneira que os frequentadores das páginas, acabam que elegendo eles como úteis. Sendo assim a aplicação dessa ferramenta permite maior rapidez e facilidade para os sites exibirem anúncios Google considerava a essência de cada página, capitalizando-as.

\section{Método}

De acordo com Martins (2004) pode-se definir como pesquisa qualitativa "aquela que privilegia a análise de micro processos, através do estudo das ações sociais individuais e grupais, realizando um exame intensivo dos dados, e caracterizado pela heterodoxia no momento da análise".

Quanto aos objetivos essa pesquisa pode ser caracterizada como descritiva. Para Gil (2008) a pesquisa descritiva é aquela que descreve as características de determinadas populações ou fenômenos. Uma de suas particularidades está na utilização de técnicas padronizadas de coleta de dados, tais como o questionário e a observação sistemática.

Quanto aos meios, a pesquisa pode ser caracterizada como bibliográfica e estudo de multicasos. Bibliográfica, pois para fundamentação teórica do trabalho foi realizada investigação sobre os assuntos pertinentes ao tema e aos objetivos da pesquisa. Já o estudo de multicasos se caracteriza pelo caráter de profundidade e detalhamento, focando esforços em uma unidade de análise.

Pesquisas de multicascos permitem que o pesquisador explore dois ou mais casos sem, posteriormente, precisar comparar os resultados achados entre os cenários estudados. São 
estudos que buscam pesquisar um instrumento de estudo, algo individual, mesmo que adiante possa existir semelhanças com outros casos, trazendo a realidade de forma íntegra e profunda (TRIVIÑOS, 1997).

De acordo com Silveira (2004) o estudo de multicasos tem a vantagem de destacar similaridades e divergências entre realidades diferentes, tornando-o recomendável para que se caracterize uma descrição mais profunda e analítica da formulação de estratégias em organizações similares, mas não homogêneas como são as agências estudadas.

A pesquisa foi realizada em 3 estabelecimentos localizados na cidade de Crato-CE, sendo aqui denominados como empresa A, B e C. O setor de atuação de ambos é voltado para a área de bares e restaurantes de modo geral oferecendo a todos os públicos o melhor de seus serviços.

A amostra da pesquisa foi montada a partir de conveniência, com os gerentes, ou com os próprios donos dos estabelecimentos referidos.

Segundo Oliveira (2001) a amostragem por conveniência é indicada e frequentemente utilizada para a criação de ideias em estudos exploratórios, principalmente.

A amostragem por conveniência é um tipo de amostragem não probabilística. Uma de suas características é a escolha de elementos que estejam imediatamente disponíveis. Nela os elementos da população não tem a mesma probabilidade de serem escolhidos (MAYER, 2016).

Como critério de inclusão foram escolhidos estabelecimentos localizados na cidade de Crato-CE, do ramo de bares e restaurantes, com um número expressivo de frequentadores. Foram excluídos aqueles nos quais não fossem do ramo pré-estabelecido e que tinham uma baixa frequência de consumidores.

Foi realizada uma entrevista, por meio de um roteiro estruturado com os gestores, ou com os próprios donos dos estabelecimentos, para a coleta de dados (Apêndice A). Os dados coletados na entrevista foram anotados no momento da ocorrência da mesma, não havendo a necessidade de gravação.

O momento da análise dos dados é o mais crucial da pesquisa, pois, é através dela que serão expostos os resultados e a conclusão do estudo, tal conclusão poderá ser final ou parcial, dando espaço para outas pesquisas que possam vir a acontecer (MARCONI \& LAKATOS, 1996). A técnica utilizada foi a análise de conteúdo com o objetivo analisar se as empresas 
selecionadas para pesquisa, pelo método de apontamento, nas quais trabalham no seguimento de bares e restaurantes em Crato-CE, utilizavam-se das ferramentas do marketing digital.

\section{Análise e Discussão dos Resultados}

Essa sessão apresenta a análise e interpretação dos dados obtidos com a realização de uma entrevista in loco, com três gestores e/ou proprietários de empresas. Sendo o primeiro proprietário da empresa A o segundo, proprietário da empresa B e o terceiro, gestor da empresa C. Todos com atuação no ramo de bares e restaurantes na cidade de Crato-CE.

A primeira pergunta da entrevista tinha por objetivo compreender se gestor e/ou proprietário saberia informar em que classe social o público alvo do estabelecimento se enquadraria, para assim poder traçar corretas estratégias de marketing destinadas ao seu público exposto.

Quadro 1: Público alvo

\begin{tabular}{|l|l|}
\hline \multicolumn{2}{|c|}{ Qual seu público alvo? } \\
\hline EMPRESA A & $\begin{array}{l}\text { Buscamos a classe média alta identificada com a proposta do espaço, } \\
\text { em três anos de atividade, nosso público tem o seguinte perfil: } \\
\text { Profissionais liberais, Empreendedores, Executivos, Intelectuais, } \\
\text { Profissionais da educação, Artistas (de todas as vertentes) e } \\
\text { Acadêmicos, esse último em menor proporção aos demais. }\end{array}$ \\
\hline EMPRESA B & $\begin{array}{l}\text { O público alvo não foi definido, mas temos como pretensão ser de } \\
\text { todas as classes sociais. }\end{array}$ \\
\hline EMPRESA C & $\begin{array}{l}\text { Pessoas que pertencem a classe A e B, economicamente ativas, na } \\
\text { região do Crajubar. }\end{array}$ \\
\hline
\end{tabular}

Fonte: Dados da Pesquisa (2018).

Com base nas referidas respostas pode-se analisar que duas empresas (a empresa A e a empresa C) das três entrevistadas, compreendem a importância que é saber a classe social que o seu público alvo está inserido, para assim traçar estratégias de marketing para os mesmos, levando vantagem sobre seus concorrentes. Já a empresa B, embora localizada em um bairro de classe média alta, demonstra desconhecer a importância desse método e o quão ele o auxiliaria 
na gestão do estabelecimento. Nesse contexto, Cobra (2017) ressalta a importância do marketing como fator preponderante a identificação de seu público alvo para a geração de lucro.

A segunda pergunta tinha como propósito verificar se as referidas empresas estavam atentas as novidades nos métodos utilizados no marketing digital.

Quadro 2: Novidades Marketing Digital

A empresa está atenta às novidades a respeito de métodos de marketing digital?

\begin{tabular}{|l|l|}
\hline EMPRESA A & Não como deveria. \\
\hline EMPRESA B & Não, o marketing da empresa não está como foco principal. \\
\hline EMPRESA C & Sim. \\
\hline
\end{tabular}

Fonte: Dados da Pesquisa (2018).

Por meio dessas respostas é possível averiguar que o proprietário da empresa A admite que não está atento a novidades, mas concorda com a importância de tal pratica. O proprietário da empresa B, demonstrou a partir de sua resposta um total desconhecimento da importância do marketing e de suas ferramentas para um estabelecimento e o quão ele poderia ser útil para a barganha de cliente por parte do mesmo. $\mathrm{O}$ gestor da empresa $\mathrm{C}$, assim como o proprietário da empresa A reconhece a importância de estar atento as novidades do marketing digital e a sua utilização. O marketing digital tem se mostrado a cada dia bastante eficaz, principalmente com a conectividade que existe atualmente, utilizando-se da internet e de inovações tecnológicas direcionadas a comunicação, vem reformulando o pensamento do consumidor, fazendo com que os produtos e/ou serviços sejam vistos de qualquer lugar (OLIVEIRA, 2011).

A terceira pergunta tinha como proposito entender se as empresas teriam um setor específico destinado ao marketing digital ou se esse era terceirizado. 
Quadro 3: Especifico ou Terceirizado

\begin{tabular}{|l|l|}
\hline Você tem um setor especifico que cuida dessa área ou terceiriza esse serviço? \\
\hline & $\begin{array}{l}\text { Não, no meu entendimento, uma empresa de pequeno porte deve ter } \\
\text { a multifuncionalidade bem presente por conta dos custos, } \\
\text { principalmente nos anos iniciais do negócio, deve se segmentar as } \\
\text { funções ligadas diretamente a atividade, e designar alguém } \\
\text { capacitado ou com habilidades na equipe para duas ou mais funções. } \\
\text { EMPRES sentido o marketing (digital ou não) deve ser muito bem } \\
\text { avaliado. Entendo como necessário, mas os altos custos para se } \\
\text { manter um profissional (regularizado) apenas nesse setor deixam } \\
\text { incertezas no tocante a essa proposta. }\end{array}$ \\
\hline EMPRESA B & Não. \\
\hline EMPRESA C & Não. \\
\hline
\end{tabular}

Fonte: Dados da Pesquisa (2018).

Sendo $100 \%$ das repostas, para essa questão, negativas, conclui-se que o marketing digital, realizado pelos estabelecimentos, ainda é uma prática amadora, pois não possuem nenhum colaborador especializado na área, como também nenhum serviço de terceirização para este fim, embora haja a compreensão, por parte de um dos gestores, a respeito da importância e dos custos de tal investimento. Os altos custos foram alegados por uma das empresas, vale a pensa ressaltar que pode-se considerar não como custo mas sim como investimento, pois possuem ferramentas mais baratas que o marketing de massa e que proporcionam ao gestor uma mensuração dos resultados. Segundo Torres (2009), a "exploração" de seus clientes pode ser uma saída para os tais custos, criando formas que façam com que eles compartilhem as divulgações em suas redes sociais de forma gratuita, o que pode assim beneficiar o estabelecimento.

A quarta pergunta tinha como objetivo entender como as empresas analisavam os dados de retorno do investimento em marketing digital, como foi constatado nas respostas da pergunta anterior, onde tal prática não era realizada pelas empresas de forma profissional e sim totalmente amadora, logo, as respostas para essa questão foram: 
Quadro 4: Analise de Dados

\begin{tabular}{|l|l|}
\hline \multicolumn{2}{|c|}{ De que forma vocês analisam os dados? } \\
\hline EMPRESA A & Não \\
\hline EMPRESA B & $\begin{array}{l}\text { Não podemos perceber o quanto de retorno teve com esse } \\
\text { investimento de marketing, pois no momento não tem métodos } \\
\text { específicos para saber dos resultados. }\end{array}$ \\
\hline EMPRESA C & Por meio de ferramentas digitais, gráficos, interação, entre outros. \\
\hline
\end{tabular}

Fonte: Dados da Pesquisa (2018).

Por mais amador que seja o marketing (digital ou não) deve-se ser aplicado alguma ferramenta de medição, pois a partir dessa será possível saber quanto de tempo ou dinheiro foram gastos com tal ação como também constatar se a investida está oferecendo retorno ou não, até as mais simples e baratas ferramentas como Facebook e YouTube, permitem que o gestor mensure o retorno desse investimento, porem a falta de pratica ou até mesmo o desconhecimento dessas ferramentas, fazem com que os empresários não tenham um controle sobre tais ações. A medição da aplicação de recursos e de seu retorno, sempre foram medidos, modernizando-se com o passar dos anos, a importância dessa pratica se torna de suma importância para o gestor que poderá controlar seus custos, seguindo a velha risca da administração "Redução de custos e maximização de lucro" (LAS CASAS, 2017).

As redes sociais é uma das mais importantes ferramentas de marketing digital atualmente, de acordo com Hasgall e Shoham (2007), o sucesso das redes sociais se dá pela transformação do conhecimento planejado em explícito, ao mesmo momento em que esse conhecimento se torna acessível e compartilhável por qualquer usuário. Isso mostra que a tecnologia não está a serviço apenas da manutenção dos processos de controle e de modelo hierárquico de estrutura. Dessa forma a quinta pergunta tinha a intenção de saber se as empresas possuíam contas em redes sociais e quais eram. 
Quadro 5: Redes Sociais

\begin{tabular}{|l|l|}
\hline \multicolumn{2}{|c|}{ Possuem contas em redes sociais, se sim, quais? } \\
\hline EMPRESA A & Sim, Facebook e Instagram. \\
\hline EMPRESA B & Sim, Facebook e Instagram. \\
\hline EMPRESA C & Sim, Facebook e Instagram. \\
\hline
\end{tabular}

Fonte: Dados da Pesquisa (2018).

É compressível que as respostas tenham sido as mesmas, pois as duas opções são de redes sociais nas quais possuem o maior número de pessoas com contas ativas no meio digital, pertencentes ao mesmo criador/proprietário, Mark Zuckerberg. Outro motivo plausível pelo qual as empresas podem ter optado por tais redes sociais são de que essas não requerem nenhum tipo de especialização para sua operacionalização, podendo assim utilizar seus próprios seguidores como divulgadores de seu trabalho, evitando gastos com tal serviço.

Tendo em vista que as referidas empresas usufruem das maiores redes sociais para divulgarem seu trabalho, mesmo que de forma iniciante, a sexta questão tinha o propósito de aprofundar-se mais, querendo descobrir se as mesmas utilizavam-se de outras ferramentas do marketing digital que não fossem as redes sociais.

Quadro 6: Outros métodos

\begin{tabular}{|l|l|}
\hline \multicolumn{2}{|c|}{ Utiliza de outros métodos de marketing digital? } \\
\hline EMPRESA A & $\begin{array}{l}\text { Lista de clientes no aplicativo de conversa WhatsApp com cerca de } \\
400 \text { clientes cadastrados. }\end{array}$ \\
\hline EMPRESA B & Utilizamos da plataforma Cariri Delivey. \\
\hline EMPRESA C & Utilizamos apenas aplicativos de Delivery. \\
\hline
\end{tabular}

Fonte: Dados da Pesquisa (2018).

Com isso percebe-se que o proprietário da empresa A está mais antenado no mercado, com a utilização do aplicativo WhatsApp que permite o empresário ter conversas diretas com 
seus clientes, propondo melhorias, promoções, recebendo feedbacks, mantendo o contato constantemente com seus clientes e parceiros, embora as dificuldades aqui relatadas sejam grandes, mas procurar soluções para tais problemas é de vital importância para o seguimento organizacional. Embora as empresas B e C também estejam andando, mesmo que lentamente, por esse caminho, essas poderiam explorar algumas ferramentas gratuitas e que trariam muitos benefícios. Além da utilização de aplicativos de Delivery que também é uma boa forma de divulgação, pois poderá levar o produto até o cliente e impressiona-lo diretamente, mas existem outras ferramentas gratuitas que também são muito eficazes, como o aplicativo WhatsApp utilizado pela empresa A, que permite manter um contato constante com o cliente, mantendo-o atualizado sobre o estabelecimento, sites próprios, que se forem administrados corretamente juntamente com a utilização de ferramentas como Google Adwords, Google Adsense, fara com que o estabelecimento recebe dinheiro por isso, retornando o investimento.

Para Churchill e Peter (2013), existem outras formas de se explorar o marketing digital, além das redes sociais, os proprietários e gestores devem estar atentos cada vez mais de ferramentas que possam acima de tudo fidelizar e satisfazer os clientes.

A sétima questão buscou entender se os gestores e/ou proprietários das referidas empresas teriam notado alguma melhoria no movimento do estabelecimento a partir do momento em que se optou pela utilização do marketing digital.

Quadro 7: Melhora no estabelecimento

\begin{tabular}{|l|l|}
\hline \multicolumn{2}{|c|}{ Após optar pela utilização do marketing digital, percebeu alguma melhora no } \\
movimento da casa?
\end{tabular}

Fonte: Dados da Pesquisa (2018). 
Com a análise dessas respostas podemos observar que as empresas A e C estão mais propicias a aceitar e utilizar as ferramentas do marketing digital como estratégia de marketing, ao contrário da empresa $\mathrm{B}$, que reluta em aceitar que o marketing digital que pode ser um importante aliado em sua gestão, potencializando seu planejamento estratégico, tal afirmação pode ser confirmada por Torres (2009), no qual fala que o marketing digital se utiliza da comunicação, publicidade, propaganda e todas as possibilidades que o marketing pode oferecer e que já são praticadas por inúmeras empresas mundialmente conhecidas.

A autocritica se torna muito importante quando decide-se tomar decisões, mudar, descobrir novos ares, com ela podemos nos avaliar para saber se estamos aptos para tais mudanças. Com base nisso foi formulada a oitava questão que pediu para avaliarem em que nível estava a utilização do marketing digital por suas próprias empresa.

Quadro 8: Autocritica

\begin{tabular}{|l|l|}
\hline \multicolumn{2}{|c|}{ Com sinceridade avalie o uso de métodos de marketing digital pela sua empresa } \\
() Péssimo () Bom () Regular () Ótimo
\end{tabular}

Fonte: Dados da Pesquisa (2018).

Como já foi relatado em questões anteriores, o proprietário na empresa $\mathrm{B}$, desconhece totalmente os benefícios que trazem a utilização do marketing digital, embora tenha tido alguns lampejos de iniciação nesse meio, com a resposta da última pergunta, mostrou total despreparo por parte do proprietário, ao contrário das empresas A e C que admitem o amadorismo da prática e são realistas em suas respostas, estando dispostos a mudanças e integralização do marketing digital como estratégia. Segundo Chaffey et al., (2009), o marketing digital pode proporcionar uma expressiva redução de custos para as empresas, e muitos outros benefícios como uma maior visualização da marca, maior conectividade com seu público alvo, fazendo-se uma empresa onipresente sendo acessada por todas as partes. 
Após se auto avaliar, é imprescindível que a empresa avalie os próprios concorrentes, para assim, saber em que nível ela está perante as atividades do mercado, com base nesse contexto foi elaborada a nona questão.

Quadro 9: Desempenho dos concorrentes

\begin{tabular}{|c|c|}
\hline \multicolumn{2}{|c|}{$\begin{array}{c}\text { Como você avalia o desempenho de seus concorrentes a respeito do marketing } \\
\text { digital? }\end{array}$} \\
\hline EMPRESA A & Melhores que o meu. \\
\hline EMPRESA B & $\begin{array}{l}\text { Admitimos que nossos concorrentes estão bem à frente de nós, no } \\
\text { que se refere ao quesito marketing digital. }\end{array}$ \\
\hline EMPRESA C & Não temos informações suficientes para julgar nossos concorrentes. \\
\hline
\end{tabular}

Fonte: Dados da Pesquisa (2018).

Com base nas respostas das empresas podemos observar que as empresa A e B, admitem que seus concorrentes estão à frente deles nessa modalidade, já a empresa $\mathrm{C}$ não está se atentando para isso, o que poderá fazer com que sofra consequências em um futuro não muito distante. Acompanhar o desempenho de seus concorrentes em qualquer que seja o quesito, cria indicadores de vital importância para a continuidade empresarial, pois com eles, a empresa poderá tomar decisões estratégicas, mantendo a concorrência e a disputa pelo mercado e pelos consumidores mais acirrada, quando isso não ocorre, a empresa fica vulnerável perante as demais, perdendo seu lugar no mercado, podendo levar o fechamento prematuro de suas portas. Deste modo Kotler e Armstrong (2003, p.474) A concorrência que as empresas de hoje enfrentam é a mais acirrada de todos os tempos [...]. Para vencer no mercado de hoje, elas precisam transformar-se em peritas não apenas na construção de produtos, mas também na construção de clientes. A solução está em executar o trabalho de entregar valor e satisfação para o cliente melhor do que os concorrentes.

A décima questão buscou entender quais as principais dificuldades que as empresas enfrentam ou enfrentaram quando falamos em implantação das estratégias de marketing digital. 
Quadro 10: Principais dificuldades

\begin{tabular}{|c|c|}
\hline \multicolumn{2}{|c|}{$\begin{array}{c}\text { Quais são/foram as principais dificuldades para a implantação das estratégias de } \\
\text { marketing digital na sua empresa? }\end{array}$} \\
\hline EMPRESA A & $\begin{array}{l}\text { Primeiro - A inviabilidade de um profissional da empresa } \\
\text { diretamente focado nesse seguimento; } \\
\text { Segundo - O alto custo das agências ou profissionais da área; } \\
\text { Terceiro - A falta de criatividade e inovação de quem atua na área, } \\
\text { muitas vezes querem ter alcance e visibilidade, e boa aparência no } \\
\text { material, mas nem sempre isso reflete a imagem ou a proposta da } \\
\text { contratante. As pessoas sabem como fazer, como fazer chegar ao } \\
\text { público, mas o material apresentado é só mais um; } \\
\text { Proposta - Consultores de marketing digital que entendam e tentem } \\
\text { transmitir a essência do negócio nos anúncios. Profissionais que } \\
\text { recebam por resultados efetivos. } \\
\text { Para ser mais claro: Um flyer ou anúncio nas redes sociais poderia } \\
\text { tem um pequeno link "imprima esse voucher, apresente a um } \\
\text { atendente e ganhe algo (desconto, cortesia, brinde), assim } \\
\text { poderíamos mensurar o quão efetivo foi o sucesso das ferramentas } \\
\text { de marketing digital remunerar esse profissional por metas de } \\
\text { vouchers recebidos. }\end{array}$ \\
\hline EMPRESA B & $\begin{array}{l}\text { A resistência dos colaboradores táticos e estratégicos para } \\
\text { adaptarem-se a uma nova ferramenta, deixando de lado a forma } \\
\text { clássica de propaganda, tais como panfletos, carros de som, } \\
\text { propaganda em rádio e entre outros. }\end{array}$ \\
\hline EMPRESA C & Produção de conteúdo de qualidade. \\
\hline
\end{tabular}

Fonte: Dados da Pesquisa (2018).

As dificuldades sempre irão existir independe do negócio ou ramo de atividade, sendo altos custos, despreparo de colaboradores, despreparos de empresas que se dizem especializadas, mas na verdade não cumprem seu papel. Enfim, todas essas dificuldades podem ser observadas ao longo das respostas do questionário, sendo, infelizmente, esse cenário mais comum nos dias de hoje. Com isso pode-se observar que a empresa A cita algumas dificuldades recorrentes e também já faz uma proposta, mostrando que mesmo ela não praticando ativamente o marketing digital, ela tem uma vivencia de mercado indicando alguns pontos onde a pratica poderia melhorar, a empresa B ainda se mostra muito resistente a mudança, desconhecendo os benefícios da pratica do marketing digital. A empresa $\mathrm{C}$, assim como a $\mathrm{A}$, conhece do mercado, 
sabe da importância do marketing digital e está disposta a praticar efetivamente a modalidade, mas enfrenta as mesmas dificuldades que praticamente todas as empresas que estão iniciando a prática do marketing digital, enfrentam. Deste modo o problema geral na gestão do marketing de pequenas empresas consiste no fato de os gerentes-proprietários terem o conhecimento do produto ou serviço que está sendo oferecido aos clientes, mas não dominarem ações da área de marketing e, portanto, terem dificuldades em implementar ações de marketing tornando-se muito difícil a prática. (GILMORE et al., 2012).

\section{Considerações Finais}

Devido às mudanças ocorridas no comportamento do consumidor, provocadas pelas inúmeras facilidades que a internet promove e seu uso progressista, o marketing digital tem sido cada vez mais utilizado por empresas que vislumbram um crescimento no mercado e almejam uma maior interação com seus clientes, fazendo com que sua visibilidade cresça com muito mais força e rapidez.

Esse meio de comunicação possui inúmeras ferramentas aqui já citadas, que são: Redes Sociais, YouTube, Google Adwords, Gooogle Adsense entre outras. O uso dessas ferramentas pode ser muito satisfatório para as empresas, já que nesse universo online, dependendo da prática, o custo pode ser bem reduzido e as facilidades que a maior interação com o cliente irá proporcionar, aumentará as chances de fidelização por parte dos mesmos.

Entretanto mesmo com todos os benefícios ganhos com o exercício da modalidade, as empresas têm que estar preparadas para entrar nesse mundo virtual, já que o consumidor, hoje, não se permite ludibriar com tanta facilidade. Ele é bem exigente e não acredita em qualquer tipo de conteúdo ou informação. Por isso para se obter sucesso com o marketing digital é necessário conhecer profundamente o público alvo, interagir com ele através de redes sociais, aplicativos de conversas, mostrar a ele conteúdos interessantes que possam chamar a atenção, realizar promoções, campanhas, oferecer serviços que supram suas necessidades e os satisfaçam buscando um relacionamento perdurável.

Por meio deste trabalho pode-se constatar que por mais simples que seja a utilização do marketing digital ele requer um conhecimento para que se possa obter um retorno favorável a 
empresa, ferramentas de medição se tornam essenciais para isso, fazendo com que tenham os custos com relação a prática, sob controle.

Os resultados deste trabalho apontaram que as empresas pesquisadas utilizam-se do marketing digital ainda seja de forma amadora, ele vem sendo praticado constantemente, mostrando que não importa o tamanho da organização, o marketing digital auxilia no relacionamento com os clientes e ajuda no crescimento organizacional. Verificou- se ainda que ocorreram mudanças positivas, para os respectivos estabelecimentos a partir do momento em que se optou pelo uso das mídias digitais como estratégia de marketing. Ressalta-se, todavia, que as empresas não utilizam indicadores que demonstrem os resultados das mídias digitais nos estabelecimentos. Os resultados apontam ainda que as principais dificuldades para a implantação das estratégias de marketing digital nas organizações são de cunho financeiro, em manter um funcionário exclusivo para essa função, e também o alto custo na contratação de uma empresa especializada nesse tipo de serviço para a produção de conteúdo digital de qualidade, embora a pesquisa referenciada mostra que tal gasto se trata de um investimento e não um custo, tendo em vista que o marketing digital possui algumas ferramentas em que retorno financeiro imediato.

Mediante ao que foi exposto, esta pesquisa cumpriu seu propósito, atingindo os objetivos apresentados nesse trabalho. Os resultados aqui apresentados não podem ser generalizados, por ser um estudo multicasos com limitação na amostra, pelo fato de não haver um tempo hábil para a coleta de uma maior amostra para resultados mais eloquentes, ficando assim como sugestão para posteriores pesquisas a utilização de uma maior amostra, para obter um resultado mais abrangente no tocante a prática do marketing digital em bares e restaurantes.

\section{Referências}

AMARAL, S. A. Marketing da informação na Internet: ações de promoção. Campo Grande: Ed. Uniderp, 2004.

ARAÚJO, A. N.; SANTOS, C. A. C. M. A contribuiçãa da indexação no processo de seleção de palavras-chave para o google adwords. VI Seminário de Pesquisa em Ciência da Informação do PPGCI. São Paulo, v. 13, n. esp., p. 109-114, set. 2017. 
BIANCOVILLI, P. et al. O Oráculo de Mountain View: o Google e sua cartografia do ciberespaço. Revista da Associação Nacional dos Programas de Pós-Graduação em Comunicação. Agosto, 2006.

BRITO, D. S.; MALHEIROS, T. C. A importância das mídias sociais e das ferramentas gratuitas do google no mercado de e-commerce no Brasil para microempresas. C@LEA - Revista Cadernos de Aulas do LEA, Ilhéus, n. 2, p. 1 - 18, nov. 2013.

CHAFFEY, D.; ELLIS-CHADWICK, F.; JOHNSTON, K. Internet Marketing. 4. ed. 2009.

CHURCHILL J. G.; PETER, J. P. Marketing - Criando Valor Para o Cliente. 3. ed. São Paulo: Saraiva, 2013.

CINTRA, F. C. Marketing Digital: a era da tecnologia on-line. São Paulo, Investigação, v. 10, n. 1, p. 6-12, 2010.

COBRA, M. Administração de marketing no Brasil. $3^{\circ}$ edição, Rio de Janeiro, 2009.

COBRA, Marcos; URDAN, André Torres. Marketing Básico. 5. ed. São Paulo: Atlas, 2017.

CASAS, A. L. L 9. ed. São Paulo: Atlas, 2017.

FOLHA DE SÃO PAULO. Número de smartphones em uso no Brasil chega a 168 milhões, diz estudo. Disponível em: <https://www1.folha.uol.com.br/mercado/2016/04/1761310-numero-de-smartphonesem-uso-no-brasil-chega-a-168-milhoes-diz-estudo.shtml>. Acesso em: 23 jul. 2018.

GILMORE, A.; KRAUS, S.; O’DWYER, M.; MILES, M. Editorial: Strategic marketing management in small and medium-sized enterprises. International Entrepreneurship and Management Journal, v. 8, n. 2, p. 141-143, 2012.

GABRIEL, M. Marketing na era digital: conceitos, plataformas e estratégias. São Paulo: Novatec, 2010.

GIL, A. C. Como elaborar projetos de pesquisa. 4. ed. São Paulo: Atlas, 2008.

HASGALL, A., SHOHAM. S. Digital social network technology and the complex organizational systems, VINE: the journal of information and knowledge management systems. 2007.

JUE, A. L., MARR, J. A. \& KASSOTAKIS, M. E. Mídias sociais nas empresas: colaboração, inovação, competitividade e resultados. São Paulo: Ed. Évora, 2010.

KOTLER, P.; ARMSTRONG, G. Princípios de marketing. 9. ed. São Paulo: Prentice Hall, 2003.

KOTLER, P.; KELLER, K. L. Administração de Marketing. 12. ed. 2006.

KOTLER, P. Marketing 4.0 do tradicional ao digital. Rio de Janeiro: Sextante, 2017.

MARCONI, M. A; LAKATOS, E. M. Técnicas de pesquisa: planejamento e execução de pesquisas, amostragens e técnicas de pesquisas, elaboração e interpretação de dados. 3.ed. São Paulo: Atlas, 1996. 
MARTINS, H. H. T. S. Educação e Pesquisa. São Paulo, v.30, n.2, p. 289-300, maio/ago. 2004.

MAYER, F. P. Introdução à Estatística e conceitos de amostragem. Paraná, 2016.

MIRANDA, C. M. C.; ARRUDA, D. M. O. A evolução do pensamento de marketing: uma análise do corpo doutrinário acumulado no século XX. RIMAR- Revista Interdisciplinar de Marketing. Fortaleza, v. 3, n.1, p- 40 - 57, jan/jun, 2004.

MOREIRA, A. G.; PEDROSO, B. G.; ROCHA, C. M.; VIEIRA, R. D. H. Marketing e sua relação com o púbico infantil. Rev Cient Online Tecnologia - Gestão - Humanismo. V.2, n. 1. FATEC Guaratinguetá - SP. 2013.

SILVEIRA, A. A. Gestão do conhecimento com ênfase na aprendizagem organizacional: um estudo multicaso no contexto bancário. Itajubá, 2004.

OLIVEIRA, L. A. Estratégias digitais de marketing orientadas à performance das instituições. 2011. 51f. Monografia (Bacharelado em Administração) - Universidade de Brasília, Departamento de Administração, 2011.

OLIVEIRA, T.M.V. Amostragem não probabilística: adequação de situações para uso e limitações de amostras por conveniência, julgamento e quotas. Fundação Escola de Comércio Álvares Penteado FECAP . Revista de Administração Online. V. 2, n. 3, jul./ ago./set. 2011.

REINO, L. S. A. Redes Sociais e Marketing Digital, o Caso do Firula's Café. 2010.

RECUERO, R. Redes Sociais na Internet. Porto Alegre: Ed. Sulina, 2009.

SANTOS, F. A. Marketing na Era Digital: Análise da marca Chico Rei. Juiz de Fora Fevereiro de 2014.

SINCLAIRE, J. K.; VOGUS, C. E. Adoption of social networking sites: an exploratory adaptive structuration perspective for global organizations. Information Technology and Management. V. 12, n.4, 2011.

TORRES, C. A bíblia do marketing digital: tudo o que você queria saber sobre marketing e publicidade na internet e não tinha a quem perguntar. São Paulo: Novatec, 2009.

TRIVIÑOS, A. N. S. Introdução à pesquisa em ciências sociais: a pesquisa qualitativa em educação. São Paulo: Atlas, 1997.

Como citar este artigo (Formato ABNT):

ARAÚJO, Jackson Bruno Feitosa; ALBUQUERQUE, Joyce da Silva. Marketing Digital: Um Estudo Multicasos em Bares e Restaurantes de Crato-CE. Id on Line Rev.Mult. Psic., 2018, vol.12, n.42, p. 719-742. ISSN: 1981-1179.

Recebido: 18/10/2018;

Aceito: 19/10/2018 